\title{
TRAYECTORIA CRÍTICA DE JOSÉ FERNÁNDEZ MONTESINOS
}

\author{
Francisco Abad
}

Universidad Nacional de Educación a Distancia

\section{PARA UNA HISTORIA DE LA CRÍTICA}

La trayectoria de las ideas crítico-literarias en España no es bien conocida por lo que se refiere a los siglos XIX y XX: el análisis de conjunto está donde lo dejó Menéndez Pelayo. Esto es bien sabido, y nosotros lo hemos repetido varias veces; no obstante, se suele decir menos (o no se dice en absoluto) que tal preterición se debe en parte a un rechazo global del Ochocientos español, Ochocientos tomado en sentido amplio — hasta 1939-.

Efectivamente como todo global nuestro siglo XIX y el primer tercio del XX suelen quedar desatendidos en sus aspectos filológicos: además de las ideas estéticas, la historia de la lengua y la de las ideas lingüísticas resultan poco conocidas en una visión de conjunto. Estamos ante la inercia pedagógicamente arraigada del estudio de otras épocas, el cual 
resulta en definitiva un tanto más cómodo - algo hay de esto-, y asimismo ante una preterición del siglo liberal; para el estudio de las letras bellas del XIX hace falta además un conjunto de datos eruditos e histórico-políticos que dificultan objetivamente la tarea.

La conciencia española no ha asimilado muchas veces la centuria del Ochocientos, y podemos mostrarlo con un dato de los mismos días en que ultimamos las páginas presentes. Una reseña periodística nos da noticia de la conferencia pronunciada por el historiador Carlos Seco, conferencia dada ante autoridades políticas relevantes y que vemos responde más o menos a un texto escrito suyo de hace poco (Seco, 1996); pues bien, atendiendo al texto escrito y más fiable observamos cómo respecto de la España posterior a 1835 se habla de un «triste panorama», y luego del sexenio democrático en tanto «sexenio de perturbaciones». Más tarde en 1931 «lograba su triunfo definitivo» lo que el autor denomina «el regeneracionismo rupturista» (1996: 26-27).

Tenemos gusto en reconocer la asombrosa continuidad en el trabajo del prof. Seco, pero creemos que su perspectiva sobre la España de 1808-1939 tiene un sesgo muy matizado negativamente hacia algunas etapas y protagonistas; por ejemplo la visión del sexenio que nos ha dado José M. . Jover resulta menos unilateral y más alentadora.

En todo caso queríamos sugerir cómo en efecto nuestra centuria liberal despierta aún reservas inclusos en historiadores maduros y capaces. Por lo que respecta a lo filológico, la lengua y las ideas linguiísticas y literarias del período parecen importar menos.

Dar noticia de los críticos literarios del Veintisiete supone contribuir en algo al deseado panorama de los estudios literarios en España durante las dos centurias últimas: en este sentido podemos referirnos a Amado Alonso, o a Dámaso Alonso, etc.; nosotros vamos a dar aquí alguna noticia de don José Fernández Montesinos.

\section{SEMBLANZA INICIAL}

En los Ensayos y estudios de literatura española cuya edición cuidó Joseph Silverman aparece una nota biográfica acerca de Montesinos, algunos de cuyos datos nos sirven útilmente para enmarcar a nuestro autor; escribe así Silverman en la nota «José F. Montesinos»: 
Entre 1917-1920 trabaja en el Centro de Estudios Históricos bajo la dirección de don Américo Castro [...]. A partir de 1920 es Lector en la Universidad de Hamburgo [...] A fines de 1932 regresa a Madrid para incorporarse a la Universidad Central como Encargado de Curso [...] A raíz de la entrada de los nazis en París es nombrado Lector en la Universidad de Poitiers [...] En 1946, invitado por la Universidad de California en Berkeley, se traslada a ella [...] Profesor emérito ahora en Berkeley (Montesinos, 1970: 21-24).

$\mathrm{Al}$ autor granadino vemos que le alcanzaron de lleno la guerra civil española y la guerra mundial; de hecho él mismo testimonia: «Casi nada pude escribir entre los años 1936-1946, los que hubieron debido traer mi maduración (1970:15).

Empezó en el Centro de Estudios Históricos, y por ello debe ser considerado como discípulo directo de las enseñanzas allí recibidas, y miembro así de la «escuela española» pidalina o escuela de Menéndez Pidal; en particular él era discípulo inmediato de un joven entonces Américo Castro, que fue quien le llevó al estudio de Lope, según confesión propia de Montesinos.

Nuestro autor, además de esta vinculación pidalina, tuvo otra con el mundo de ideas de Ortega y Gasset, y esto fue lo que le hizo no desatender el tiempo histórico: el buen y escrupuloso positivismo de los datos le venía del Centro de Estudios Históricos; la atención a la sustancia temporal que tiene lo humano, de don José Ortega. Montesinos no se muestra muy en acuerdo con el que denomina «formalismo crítico», ante el que estima que Amado Alonso se dejó influir; contrasta las posturas respectivas de Amado, de don Dámaso y la suya propia, y manifiesta a la letra:

Dámaso Alonso podrá preferir los análisis formales, pero nunca olvida su sólida preparación filológica, y el tiempo histórico nunca se escamotea en sus estudios. Pero yo seguía siendo más ortodoxamente orteguiano. Yo no podía olvidar que en sus años de más admirable madurez, Ortega nos enseñaba que la historia de las ciencias y disciplinas del espíritu no podía ser otra cosa que alta sociología, ya que ninguna de esas actividades podía darse en el vacío (1970:14).

Las apetencias del público condicionan la obra poética — concluye nuestro autor-, y así la Historia de las letras se convierte en «sociología literaria».

Por una exigencia u otra Montesinos se veía llevado a la erudición de lo histórico y no sólo al análisis formalista; de hecho él fue siempre 
muy erudito, y no dejó nunca de tener presente la biografía de los autores ni la incidencia de la que denominaba «fuerza receptora» en la «fuerza creadora» artística.

El autor granadino se había iniciado por tanto en el mundo filológico, bajo la iniciativa de las mejores escuelas: el Centro de Estudios Históricos de manera formal; la impronta de don José Ortega de modo más informal pero no menos eficiente. Una y otra traza le llevaban a la erudición historicista, a la Historia literaria entendida en tanto reconstrucción de la vida literaria en toda su complejidad. La complejidad de los factores o fuerzas actuantes -el tiempo histórico concreto, los autores, el público, etc.- - debía quedar atendida, y así lo aprendió y lo entendió un joven José Fernández Montesinos, según él evocaba luego pasados los años.

Pero sobre el autor se abatieron las circunstancias desencadenadas por la guerra civil española y por la guerra mundial - la familia Fernández Montesinos sabido es que resultó muy afectada por la represión nacionalista en los inicios de la contienda-, y así nuestro autor ha podido hablar con mucha razón de «el drama de mi vida», que consistía en querer lo que a veces no podía cumplir. El crítico granadino estampa en este orden de cosas las siguientes palabras: «No puedo menos de aducir en mi defensa el mote del viejo blasón castellano:

Yo he hecho lo que he podido,

Fortuna lo que ha querido" (1970:16).

A pesar de su obra muy lograda, Montesinos estima que las circunstancias le alcanzaron de modo desfavorable; desde luego así fue, aunque no por ello ha dejado de legarnos un obra escrita muy cumplida y de referencia imprescindible.

\section{UNA TRAYECTORIA INTELECTUAL}

A lo largo de su trayectoria como estudioso de las letras españolas don José Montesinos fue haciendo suyos sucesivos centros de interés o núcleos temáticos que caracterizan el trabajo que hizo. A partir de 1920 se 
dedicó mucho a Lope, y tal esfuerzo —independientemente de los textos que editó- dio forma al libro que definitivamente se rotularía Estudios sobre Lope de Vega; «Castro (dice nuestro autor, según queda anticipado) me lanzó al estudio de Lope» (1970:12). En efecto el joven Américo Castro estaba por entonces muy entregado al estudio literario del Siglo de Oro - Tirso, Quevedo, Lope, Cervantes, ...-, aunque él de manera profesional era catedrático de Historia de la lengua española: no resulta extraño que tal interés lopista lo indujese asimismo en su discípulo.

A propósito de don Américo puede hacerse además una observación, y es la de su enraizamiento intelectual en las cuestiones de la Edad de Oro; esta conformación de hábitos mentales fue seguramente la que le llevó a dirigirse a las centurias del Cuatrocientos, el Quinientos y el Seiscientos cuando trató de explicarse la guerra civil española, que según confesión propia repetida en varios escritos constituyó el motivo de las reflexiones históricas que hizo. Otro estudioso, para explicar la violencia de la España contemporánea, hubiese prestado atención al período 1808-1939, o al 1833-1939, pero Américo Castro - hecho intelectualmente en el estudio de nuestra época áurea-, se remontó a tal época y luego a las raíces medievales de la misma, para tratar de aclarar lo contemporáneo.

En todo caso vemos al joven Américo inducir en su muy joven discípulo Montesinos el afán lopeveguesco, que en el crítico granadino daría tan amplios frutos. Cabe asimismo barruntar que la inmediata dedicación al estudio de los hermanos Valdés que Montesinos también desarrolló en los años veinte, no fue ajena a la impronta ideológica del erasmismo que por igual caracterizó a don Américo y en general al Centro de Estudios Históricos: no resulta nada extraño que un discípulo de Américo Castro de la época de la escuela pidalina, no sólo se dedicase a Lope sino asimismo a los hermanos Alfonso y Juan de Valdés.

Aún antes de la guerra de 1936 don José Montesinos escribió artículos y notas sobre distintos temas literarios españoles, del Siglo de Oro o de otras épocas: a alguno de estos escritos nos referiremos después.

\section{LOPE Y LOS VALDÉS}

De los Estudios sobre Lope de Vega el propio autor destaca el capítulo «Las poesías líricas de Lope de Vega», que en su día prologó los 
dos volúmenes de «Poesías líricas» lopeveguescas aparecidos en Clásicos Castellanos. Estos volúmenes contribuyeron a dar a conocer al Fénix a los poetas jóvenes del 27, y don José Montesinos siempre ha mostrado una legítima alegría por haber desempeñado el papel que hizo; escribe efectivamente Montesinos:

Los creadores fueron Federico García Lorca, Rafael Alberti, con otros [...] Ellos tomaron de la mano a Lope y lo volvieron a acercar al español de hoy, en versos que a veces suenan a Lope mismo [...] Pero, y esto tengo que decirlo con gran modestia, y pido perdón por decirlo, antes había venido yo, que no había escrito versos lopescos ni de otra especie, pero había sacado a luz aquellos de Lope que mi generación mejor podía entender (1969:XI).

Para el autor granadino resulta muy agradable esta evocación de los hechos: él volvió a poner en el mercado la lírica de tipo tradicional de Lope, y tal poesía estimuló a los jóvenes del Veintisiete, al igual que recibieron el estímulo del «Cancionero musical de los siglos XV y XVI» que había editado a su vez Barbieri unos lustros antes.

Junto a Lope surge naturalmente el nombre de Góngora, y nuestro crítico anota por ejemplo que el culteranismo supone un término ineluctable en el desarrollo evolutivo del problema de la forma que estaba planteado por el Renacimiento: «el culteranismo - dice- fue una solución, y como tal queda en la historia del arte» (1969:134). Estas palabras creemos que encierran un eco de Vossler, el cual en efecto entiende la diacronía artística en tanto la historia de los problemas estéticos planteados y resueltos por los creadores de belleza: la Historia del arte sólo debe valorar las obras - proponía Karl Vossler- como ensayos de resolución de problemas estéticos efectivamente planteados. Don José Montesinos entiende el culteranismo como «una solución», solución estética al problema de la forma y que se da en unos años concretos.

De manera particular advierte asimismo el crítico granadino cómo el arte lopeveguesco experimenta una contaminación «gongórica», y manifiesta así «inflexiones culteranas» (1969: 161); globalmente Montesinos evalúa al Lope lírico proponiendo que «hubo en él un clásico y un romántico y un parnasiano y un simbolista, ... y un modernista» (1969:210).

Hemos visto cómo la dedicación lopista de don José Montesinos arranca de los mismos inicios de su obra, de 1920; a fines de los mismos años veinte nuestro autor dedicó también el afán en el estudio a 
una segunda temática, la de los erasmistas españoles: Montesinos editó con introducciones eruditas y sucesivamente el Diálogo de la lengua de Juan de Valdés, el Diálogo de las cosas ocurridas en Roma y el Diálogo de Mercurio y Carón de Alfonso de Valdés, y unas Cartas inéditas de Juan de Valdés al Cardenal Gonzaga. Durante muchos años las únicas ediciones en las que ha sido posible leer los Diálogos valdesinos han sido justamente las de nuestro autor.

Nada debe extrañar esta dedicación a las cuestiones erasmistas por parte de Montesinos: leyendo toda su obra crítica se ve bien que él tenía una alma libre y que enlazaba de modo natural con la libertad interior de espíritu de los erasmistas españoles.

\section{LA «EDAD DE ORO»}

Junto a los temas lopeveguescos o del erasmismo en España, don José Montesinos abordó otros en los años anteriores a la guerra civil, y surgieron así artículos o notas que luego dieron lugar a los Ensayos y estudios de literatura española. En 1934 reaccionaba por ejemplo frente a Pfandl, quien acaso añoraba la ortodoxia unánime de la «Edad de Oro», y pedía en consecuencia una interpretación de nuestro pasado hecha con originalidad por autores españoles y llevada a cabo con criterios adecuados:

\footnotetext{
Vivimos — proclamó Montesinos-en la urgencia de elaborar nuestros criterios, de recuperar nuestro sentido. No nos inquietarían todos los romanticismos del mundo si sintiéramos en torno nuestro una juventud entregada a esa tarea de revalorar la cultura española [...] Quisiéramos esta tarea magnifica de reconquistar a España, de hallar el sentido de España (1970:165).
}

El rechazo ante el tono ideológico adoptado por Pfandl indujo que Montesinos, en 1936, hablase de «la llamada Edad de Oro de la literatura española» (1970:58): manifestaba sin duda un distanciamiento ante lo planteado en la Historia de literatura áurea publicada por el hispanista alemán.

Los Ensayos y estudios... más los Estudios sobre Lope y las cuatro ediciones de textos de los Valdés (y las ediciones de textos de Lope) ofrecen más o menos el resultado del trabajo crítico de Montesinos anterior a la guerra española; la suma de la contienda civil más la guerra mundial hizo 
que nuestro autor pasase por años de mucho sufrimiento al igual que sabemos los pasaron otros estudiosos: las cosas sólo se recompondrían a partir de su incorporación a Berkeley, cuando - como se ha escrito- ello suponía «la vuelta a la vida».

\title{
UNA «PRIMAVERA Y FLOR»
}

Justamente en Berkeley y en Diciembre de 1953 fechaba el crítico granadino su reimpresión con estudio preliminar de la Primavera y flor de los mejores romances de 1621.

Esta «Primavera y flor» la recogió Pedro Arias Pérez y quedó editada - según decimos- en 1621; Montesinos la reimprime con muchas anotaciones eruditas, y reclama a propósito de ello la solidez documental. El párrafo de nuestro autor debemos recogerlo a la letra:

\begin{abstract}
Cataloguemos los manuscritos existentes, sus variantes, las atribuciones que contengan [...] Cuando poseamos indicios sobre la autoría que de cada poema existen, y mil cosas más, podremos entregarnos con fruición al juego de clasificar los artificios retóricos en que el autor pudo complacerse, el engarce de las palabras, el colorido de los fonemas. Hasta entonces una voz secreta estará musitando en lo más íntimo de nuestro espíritu: ¿Con quién hablo? ¿De qué hablo? ¿Qué nos deparará el manuscrito de mañana? (1954: LXXXVII-LXXXVIII).
\end{abstract}

Ya nuestro autor, en este 1953, manifestaba las preocupaciones que caben ante los formalismos críticos: muchos análisis serán mudos si antes no se ha hecho (y se ha hecho bien) una labor erudito-editorial. Trabajar sin claridad porque no conocemos lo necesario de los textos, supone indudablemente trabajar un poco a ciegas y en el vacío, es decir, sin poder alcanzar las necesarias conclusiones o sin que nuestras conclusiones posean la rigurosidad deseada.

A principios de los años cincuenta resultaba ya bien notorio el auge de los formalismos críticos, y a don José Montesinos le parecía un tanto excesivo el formalismo programático de un Amado Alonso; él estimaba más la erudición historicista junto al análisis formal que estaba haciendo Dámaso Alonso, y en particular en la presente «Introducción» a la Primavera y flor advierte sobre los riesgos de no tener aclarados antes los problemas textuales, de autoría, etc. 
Pero además el crítico granadino se refiere ahora a Lope y Góngora; él cree que puede estimarse que el centro de gravedad literario se encuentra en la obra de Lope, y así propone sobre el XVII literario estas ideas:

Pocos se hacen cargo de que el barroco español es Lope, y de que lo culterano es Lope multiplicado por el gongorismo [...] Lope, el hombre prodigioso que tenía toda España y la tradición hispánica en la uña, era capaz de todo: de producir un romance, de deshacerlo, de inventar poesía tradicional, de expulsarla de su ámbito e inventar otra [...] En la pugna Lope-Góngora, el siglo XVII decidió por Lope y Góngora. Yo diría que Lope es el cantar, ese cantar que es España, mientras que Góngora es ese sentido de la experimentación y de la aventura que es España también (1954:LXXXIXXCII).

Lope no puede ser dejado aparte a la hora de caracterizar el Barroco - viene a sugerir el autor-, pues si se tienen en cuenta todas sus maneras expresivas resulta en realidad Lope quien sintetiza verdaderamente el Barroco español: él también fue culterano. Es a Lope a quien cabe identificar con el conjunto de los rasgos y manifestaciones artísticas del Barroco (indica Montesinos ); él —añade asimismo- ocupa el centro de gravedad de la vida literaria, en cuanto llevaba las más de las iniciativas y en cuanto tenía en sí asimilada la tradición española toda.

Por supuesto ha de contarse también siempre con Góngora, y por ello el crítico granadino troquela en definitiva la fórmula de «Lope y Góngora», es decir, Lope más Góngora: la avaloración artística del período barroco ha de contar con la obra del uno y con la del otro.

Don José Montesinos incurre sin embargo en la creencia en la llamada «psicología» de los pueblos, en la creencia en la idea de los «caracteres nacionales», cuando identifica a Lope con «el cantar» y tal cantar con «España», del mismo modo que Góngora es el sentido de la «aventura» que se identifica asimismo con España. Nuestro autor se formó en años en que estaba vigente historiográficamente esta idea de los caracteres nacionales, y así esencializa la historia de España y da cuerpo a algunas de esas esencias en la obra respectiva de Lope y de Góngora.

En otro momento sabemos que Montesinos enfoca el culteranismo en tanto la solución dada a un problema estético que se han planteado los autores: razona entonces felizmente, más felizmente que cuando parece interpretarlo como una manifestación del sentido del experimento y de la aventura que caracteriza e individualiza supuestamente la esencia ( $₫$ ?) de lo español. 
Por lo demás no hace falta subrayar que la presente Primavera y flor de los mejores romances constituye una bella y erudita publicación.

\section{LA NOVELA MODERNA EN ESPAÑ}

En los años de Berkeley sacó adelante Montesinos fundamentalmente su magna serie de «Estudios sobre la novela española del siglo XIX»; en definitiva saldrían en la editorial madrileña Castalia ocho volúmenes, a los que hay que sumar el que se ocupa de Fernán Caballero y que sólo conoció una edición primera en México. Lamentablemente don José murió sin haber acabado el Galdós, del que falta la parte que se iba a ocupar de las novelas que siguieron a «Fortunata y Jacinta» y que trataría por tanto del «espiritualismo» galdosiano de hacia final de siglo -espiritualismo que de igual manera caracterizó a otros escritores-.

El conjunto de los presentes «Estudios...» de Montesinos encierra en abreviatura una teoría sobre España y la novela (materia que ocupó también a Dámaso Alonso, aunque las más de las veces uno y otro autor quedan preteridos): el crítico granadino advierte así que «la novela, invención española, tuvo en sus formas más modernas tardío advenimiento entre nosotros» (1983:XI). En España se frustran las posibilidades novelísticas desde hacia 1650 -vendrá a sugerir en definitiva Montesinos-, entre otras cosas porque la lengua literaria del Barroco no resultaba apta para la narración y el diálogo ficcionales.

Otra vez subraya nuestro autor lo que dijo varias veces, esto es, la necesidad de la más escrupulosa y exacta erudición historicista, de la perspectiva historicista: el análisis de la novela española del siglo XIX supone una incitación

a rehacer la historia literaria como lo que debe ser si quiere ser «histórica», una sociología literaria atenta a las ansias y a las ideas del creador, a los intereses de empresa, a la reacción de vastas masas de lectores (1983:XI).

No hay novela sin editor ni editor sin público, proclama otra vez don José Montesinos, y sin tener en cuenta a unos y otros se hace imposible intentar una Historia de la novela. 
En el caso de la narrativa española decimonónica el crítico granadino destaca la calidad de lo mejor de Galdós «y aún de Clarín o la Pardo Bazán» (1983:XVII). Don Benito en particular, para llegar a las alturas de Fortunata o de Ángel Guerra,

había tenido que rehacer por sí mismo la experiencia de su nación y de su siglo, penetrarse de las mejores esencias artísticas del mundo, fundirlo todo en el crisol de la gran tradición cervantina, y excederla (1983:XVII).

En concreto y sobre la fortuna española del género novelístico señala nuestro autor cómo la gran lírica española del siglo XVII estuvo muy íntimamente adscrita al genio de la lengua y resultó así «incomunicable»; señala asimismo cómo la comedia lopeveguesca se prestaba también poco «a la exportación en cuanto forma artística». Empero con la novela ocurrió otra cosa, y Montesinos - en un párrafo precioso que luego ha fecundado (creemos nosotros) a otros autores, como Dámaso Alonso o Francisco Rico- decía a la letra:

\begin{abstract}
Pero el caso de la novela, de la novela cervantina, no era el mismo. La novela se le escapa a España literalmente de la manos, y es más allá de sus fronteras donde empieza a mostrar una sorprendente fecundidad. En la Península dos enormes rémoras se oponen a sus progresos [...]: preocupaciones morales que la desvirtúan y falsean, y la boga de un estilo en prosa, el menos apto para la narración y el diálogo que pueda imaginarse [...] Ello es que desde mediados del siglo XVII apenas hay novela española que merezca este nombre [...] El nombre de España no cuenta para nada en la historia de la novela durante el siglo XVIII, aunque lo mejor que la novela europea produce entonces es español de origen (1983:2).
\end{abstract}

Don José Montesinos tiene en cuenta la historia comparada de las letras y hace advertir que contra la novela estuvieron tanto los contenidos morales y no propiamente narrativos, como un estilo poco apto para la narración misma, es decir —interpretamos-, el estilo conceptista. Empero la mejor novelística europea del Setecientos será española de origen, y nuestro autor señala de manera explícita cómo el Quijote resulto un «libro tan leído, estudiado e imitado» por Fielding (1983:9).

La novela se le escapa a España de las manos por la incompatibilidad entre narración y estilo conceptista, entre otras cosas (nos parece que sugiere Montesinos); así ha podido juzgarse luego el Buscón - por ejemplo-, como pésima novela picaresca, etc. 
Don José Montesinos hizo un planteamiento muy ambicioso en sus estudios sobre la novela española del XIX, y nos dejó nueve volúmenes de tales estudios; la teoría que llevan en sí tales tomos no debería olvidarse, y ahora hemos dado una muestra de ella: al crítico granadino no le pasó inadvertido cómo en efecto la trayectoria española de la novela se frustra hacia mitad del Seiscientos, y cómo sin embargo la novela española áurea se proyectó pronto en la novelística europea.

Todavía hemos de recordar sin embargo que para nuestro autor el costumbrismo literario decimonónico contribuyó a hacer posible la novela entre nosotros, pero a la vez le impuso graves servidumbres: las de la documentación formularia e inimaginativa. Ocurrió de esta forma — concluye el crítico- que «el jugar las "costumbres" contra el corazón de los personajes desequilibró y malparó muchas novelas que hubieran podido ser excelentes» (1980:135).

\section{FINAL}

Hemos apuntado en abreviatura la trayectoria de don José Fernández Montesinos como estudioso literario: su nombre debe estar incorporado a la Historia del análisis literario en España, y en particular al grupo de estudiosos de la escuela que hizo Menéndez Pidal en la Junta para Ampliación de Estudios anterior a la guerra. Don José Montesinos fue un ejemplo de altura ética, de honradez erudita, y de dedicación al trabajo.

\section{Referencias bibliográficas}

F. Montesinos, J. (ed.) (1954). Primavera y flor de los mejores romances. Valencia: Castalia.

F. Montesinos, J. (1969). Estudios sobre Lope de Vega. Salamanca: Anaya.

- (1970). Ensayos y estudios de literatura española. Madrid: Ed. Revista de Occidente.

- (1980). Costumbrismo y novela. Madrid: Castalia.

- (1983). Introducción a una Historia de la novela en España en el siglo XIX. Madrid: Castalia.

SECo, C. (1996). «La realidad histórica acumulada». Cuenta y Razón 100,1129. 


\section{BIBLIOGRAFÍA GENERAL DE JOSÉ FERNÁNDEZ MONTESINOS}

La Bibliografía de José F. Montesinos aparece en las pp. 39-53 de la edición de 1970 de su libro -que citamos más abajo- Ensayos y estudios de literatura española.

Destacamos de esa Bibliografía las referencias a las ediciones que hizo el autor (en sus años juveniles) en la serie de «Teatro Antiguo Español»; por nuestra parte enumeramos los principales volúmenes que escribió Montesinos, y completamos la lista que ya estaba en el libro citado.

Las referencias las damos siempre a la vista de los textos.

$$
* * *
$$

F. Montesinos, J. (ed.) (1925). Poesías líricas por Lope de Vega. I. Madrid: «Clásicos Castellanos».

- (1926). Poesías líricas por Lope de Vega. II. Madrid: «Clásicos Castellanos».

- (1928). Diálogo de la lengua por Juan de Valdés. Madrid: «Clásicos Castellanos».

- (1928). Diálogo de las cosas ocurridas en Roma por Alfonso de Valdés. Madrid: «Clásicos Castellanos».

- (1929). Diálogo de Mercurio y Carón por Alfonso de Valdés. Madrid: «Clásicos Castellanos» (De estos tres últimos volúmenes ha habido luego sucesivas reimpresiones, y de hecho han sido las ediciones en que han podido leerse hasta hace poco los respectivos textos).

- (1931). Cartas inéditas de Juan de Valdés al cardenal Gonzaga. Madrid: JAE (Lleva una «Introducción» de CXIX págs.).

- (1954). Primavera y flor de los mejores romances recogidos por el Licdo. Arias Pérez. Valencia: Castalia (Lleva una amplia "Introducción" y notas bibliográficas y críticas muy eruditas).

F. MONTESINOS, J. (1955). Introducción a una historia de la novela en España en el siglo XIX. Valencia: Castalia (En la presente «Introducción ...» -indica el autor- «quise desplegar, como una especie de obertura, los temas que hubiera desarrollado la obra de conjunto» que se proponía globalmente sobre la historia de la novela española moderna).

- (1960). Costumbrismo y novela. Valencia: Castalia.

- (1961). Fernán Caballero. México, D.F.: El Colegio de México (Es el único tomo de la serie sobre la novela del XIX que no alcanzó Montesinos a retocar y a integrar en la edición de Castalia).

- (1963). Galdós en busca de la novela. En (1973). Benito Pérez Galdós, Douglass M. Rogers (ed.), 113-119. Madrid: Taurus.

F. MONTESINOS, J. (ed.) (1964). Romancerillos tardios. Salamanca: Anaya. 
F. MonTESINOS, J. (1967). Estudios sobre Lope de Vega. Salamanca: Anaya (Se trata de la edición definitiva de esta obra, que recoge textos publicados durante más de cuarenta años de dedicación lopista).

- (1968). Galdós. I. Madrid: Castalia (El último de los estudios hechos por el autor fue el dedicado a Galdós, del que alcanzó a escribir tres volúmenes de los cuatro previstos).

- (1969). Galdós. II. Madrid: Castalia.

- (1969). Pereda o la novela idilio. Madrid: Castalia.

- (1970). Ensayos y estudios de la literatura española. Madrid: Ed. Revista de Occidente (Edición definitiva de un libro aparecido once años antes, que incorpora la bibliografía del autor hasta el tomo II de Galdós, y diferentes testimonios biográficos acerca del mismo. De manejo imprescindible para aproximarse al crítico granadino).

- (1970). Valera o la ficción libre. Madrid: Castalia.

- (1972). «Prólogo». En El Censor, E. García Pandavenes (ed.), 9-17. Barcelona: Labor.

- (1973). Galdós. III. Madrid: Castalia.

- (1977). Pedro Antonio de Alarcón. Madrid: Castalia.

- (1989). «Comentarios e impresiones». En El renacimiento cultural de la Granada contemporánea, A. Gallego Morell (ed.), 119-140. Granada: Comares.

- (1997). Entre Renacimiento y Barroco. Granada: Comares. 